\title{
Wnt3a expression is associated with epithelial-mesenchymal transition and promotes colon cancer progression
}

\author{
Lisha Qi ${ }^{1,3,4+}$, Baocun Sun ${ }^{1,2,3,4^{*}+}$, Zhiyong Liu' ${ }^{1,3,4}$, Runfen Cheng ${ }^{1,3,4}$, Yixian Li ${ }^{2}$ and Xiulan Zhao ${ }^{2}$
}

\begin{abstract}
Introduction: Epithelial-mesenchymal transition (EMT) contributes to the progression and metastasis of cancer cells and is associated with a more invasive phenotype of cancer. The $\mathrm{Wnt} / \beta$-catenin signaling pathway is one of the major pathways involved in EMT regulation. Many studies provide evidence that $\beta$-catenin, the key regulator of the canonical Wnt signaling pathway, is important in regulating EMT in cancer. However, the roles of Wnt3a, the representative canonical Wnt ligand, in EMT and colon cancer progression have not yet been fully explored.

Methods: The expression levels of Wnt3a and EMT-associated proteins (E-cadherin, vimentin, and $\beta$-catenin) were assessed by immunohistochemistry in human colon cancer tissues to evaluate the clinicopathological significance of Wnt3a, as well as the correlation between Wnt3a and EMT. We then upregulated Wnt3a expression in HCT116 colon cancer cells, established a nude mouse xenograft model, detected the expression of EMT and Wnt/ $\beta$-catenin signaling-associated proteins, and observed invasion and clone-initiating abilities.

Results: In 203 human colon cancer tissue samples, Wnt3a protein overexpression was related to colon cancer histological differentiation $(P=0.004)$, clinical stage $(P=0.008)$, presence of metastasis and recurrence $(P=0.036)$, and survival time $(P=0.007)$ of colon cancer patients. Wnt3a expression was notably concomitant with EMT immunohistochemical features, such as reduced expression of the epithelial marker E-cadherin $(P=0.012)$, increased expression of the mesenchymal marker vimentin $(P=0.002)$, and cytoplasmic distribution of $\beta$-catenin $(P=0.021)$. Results of in vitro and in vivo experiments showed that Wnt3a overexpression could alter cell morphology, regulate EMT-associated protein expression, and enhance clone-initiation and invasion. Dkk1 (antagonist of Wnt/ $\beta$-catenin signaling) could also partially reverse the expression of EMT-associated proteins in Wnt3a-overexpressing cells.
\end{abstract}

Conclusions: Wnt3a expression was associated with EMT and promoted colon cancer progression. The EMT-inducing effect was partially due to the stimulative effect of Wnt3a on the Wnt/ $\beta$-catenin pathway.

Keywords: Wnt3a, Epithelial-mesenchymal transition, Wnt/ß-catenin pathway, Colon cancer

\section{Introduction}

Colorectal carcinoma is the third most common cause of cancer-related deaths worldwide [1]. Although colorectal cancer diagnosis and treatment have significantly advanced over the past two decades, the five-year survival rate remains below $50 \%$. More than $50 \%$ of colorectal cancer cases metastasize to the lymph nodes, liver, and lungs

\footnotetext{
* Correspondence: sunbaocun2014@163.com

${ }^{\dagger}$ Equal contributors

'Department of Pathology, Tianjin Medical University Cancer Institute and Hospital, Tianjin 300060, China

${ }^{2}$ Department of Pathology, Tianjin Medical University, Tianjin 300070, China

Full list of author information is available at the end of the article
}

[2]. Thus, knowledge on the treatment of this disease would advance if its metastasis mechanism is deeply understood.

Epithelial-mesenchymal transition (EMT) is an early phase of the malignant transformation of epithelial cells. In EMT, cells lose their polarities and contacts with neighboring cells and then acquire mesenchymal-like and motile phenotypes [3]. Tumor-cell EMT is considered a crucial event in cancer metastasis. Numerous factors can reportedly induce or mediate EMT, and these factors are commonly associated with carcinoma progression.

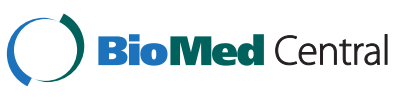

(c) 2014 Qi et al.; licensee BioMed Central Ltd. This is an Open Access article distributed under the terms of the Creative Commons Attribution License (http://creativecommons.org/licenses/by/4.0), which permits unrestricted use, distribution, and reproduction in any medium, provided the original work is properly credited. The Creative Commons Public Domain Dedication waiver (http://creativecommons.org/publicdomain/zero/1.0/) applies to the data made available in this article unless otherwise stated. 
The Wnt signaling pathway is pivotal in embryogenesis and development and is also widely implicated in a number of human diseases [4-6]. Deregulation of the Wnt signaling pathway has been associated with senescence bypass [7], aberrant cell growth [8], and cancer [9]. Signaling through the Wnt pathway starts with Wnt ligands, which consist of more than 19 closely related but distinct secreted cysteine-rich glycoproteins [10]. By activating multiple intracellular signaling cascades, Wnts control various cellular functions, including proliferation, tissue homeostasis, stem cell maintenance, and cell fate decisions [11,12]. Several Wnts such as Wnt1, Wnt3a, and Wnt7a stimulate the $\beta$-catenin-dependent pathway, called canonical Wnt signaling [12]. Other Wnts such as Wnt4, Wnt5a, and Wnt11 may activate the protein kinase $\mathrm{c}$, calcium-calmodulin kinase, or Jun $\mathrm{NH}$ (2)-terminal kinase pathway, called non-canonical Wnt signaling [13].

The canonical Wnt/ $\beta$-catenin signaling pathway is well established in colorectal oncogenesis, with $>85 \%$ of these malignancies harboring mutations along the pathway that lead to constitutive activation. Many studies provide evidence that the $\mathrm{Wnt} / \beta$-catenin signaling pathway plays an important role in EMT regulation [14,15]. However, most investigations on the effects of the canonical Wnt pathway on EMT have focused on $\beta$-catenin rather than on Wnt ligands despite the role of Wnt proteins as major initiating factors in the Wnt/ $\beta$-catenin pathway. Blavier et al. found that Wnt1 overexpression in murine mammary epithelial cells in vitro could promote EMT and cell proliferation [16]. Bo and Kanzawa have shown that increased Wnt5a provokes EMT of pancreatic cancer and gastric cancer cells $[17,18]$. Wu reported that Wnt3 activates the Wnt/ $\beta$-catenin pathway and promotes EMT-like phenotypes in trastuzumab-resistant HER2-overexpressing breast cancer cells [19]. Bao et al. found that Wnt3a could promote the EMT, migration, and proliferation of human lens epithelial cells [20]. Meanwhile, the role of Wnt3a in colorectal cancer EMT has not been fully explored.

In this study, we evaluated the clinicopathological significance of Wnt3a and analyzed the correlation between Wnt3a expression and EMT immunohistochemical features in tissue specimens from 203 colon cancer patients. The effects of Wnt3a ectopic expression in the colon cancer cell line HCT116 on the expression of epithelial and mesenchymal markers and EMT transcription factors were studied. We also investigated cell proliferation and invasion in cell cultures with Wnt3a overexpression, as well as tumor growth and metastasis in a colon cancer xenograft model. We further treated Wnt3a-overexpressing cells with a Wnt/ $\beta$-catenin pathway antagonist Dkk1-conditioned medium and detected the expression of EMT-related proteins to verify whether
Wnt3a promoted EMT by activating the Wnt/ $/$-catenin signaling pathway.

\section{Material and methods Clinical samples}

Tissue samples of colon cancer were harvested from 203 patients who had undergone surgery for colon cancer in Tianjin Medical University Cancer Institute and Hospital (Tianjin, China) between January 2002 and December 2004. None of the patients had received any chemotherapy or radiotherapy before their operation. Data of clinicopathological parameters were obtained from patients' clinical records and pathological reports.

\section{Cell culture reagents and animals}

The human colon cancer cell line HCT116 was obtained from the Cell Resource Center at the Institute of Basic Medical Sciences, Chinese Academy of Medical Sciences/ Peking Union Medical College (Beijing, China). Cells were cultured in Iscove modified Dulbecco medium with $10 \%$ FBS. Dkk1 recombinant protein was obtained from R\&D Systems. For Dkk1 administration in vitro, recombinant Dkk1 $(1 \mu \mathrm{g} / \mathrm{mL})$ was added to culture medium. Typically, $50 \%$ of the medium was replaced every $24 \mathrm{~h}$ with fresh conditioned medium containing Dkk1 at the original concentrations. Cells were harvested $48 \mathrm{~h}$ post-treatment, and total cell lysates were collected for measurement by Western blot. The micro-Boyden chambers used were from NeuroProbe (Gaithersburg, MD, USA). Antibodies to $\beta$-catenin, goat anti-rabbit, and goat antimouse IgG-FITC were from Santa Cruz Biotechnology (Santa Cruz, CA, USA). Antibodies to Wnt3a, Snail, Slug, and Twist were from Abcam (Cambridge, UK). Antibody to E-cadherin was from BD Biosciences (San Jose, CA, USA). Antibody to vimentin was from Epitomics (Burlingame, CA, USA). Phalloidin was from Invitrogen (Carlsbad, CA, USA). Alexa Fluor 488 and 546 were from Molecular Probes (Eugene, OR, USA). BALB/C nude mice (4-5 weeks old) were obtained from Wei Tong Li Hua Experimental Animal Company (Beijing, China).

\section{Immunohistochemical staining}

Streptavidin-biotin-peroxidase staining was performed as previously described [21]. In a typical procedure, the sections were pretreated with microwaves, blocked, and incubated with a series of antibodies overnight at $4^{\circ} \mathrm{C}$. Then, they were immunostained with HRP-conjugated antibody and signals were revealed using 3,3-diaminobenzidine buffer as substrate. In place of primary antibodies for the negative control, PBS was used.

The expression of Wnt3a, E-cadherin, vimentin, and $\beta$-catenin was analyzed only histologically in normal and neoplastic epithelial cells and not in stromal tissues. Wnt3a staining was considered immunoreactive 
when brown granules were identified in the cytoplasm. The staining intensity of Wnt3a was graded on a scale from 0 to 2 (0 for no staining, 1 for weak immunoreactivity, 2 for strong immunoreactivity). Percentage immunoreactivity was scored on a scale from 0 to 3 ( 0 for no positive cells, 1 for $<25 \%$ of cells being positive, 2 for $25 \%$ to $50 \%$ of cells being positive, and 3 for $>50 \%$ of cells being positive). We multiplied the two scores to obtain a composite Wnt3a expression score. Wnt3a expression was classified as negative $($ score $=0)$, weakly positive (score $=1,2$, or 3 ), or strongly positive (score $=$ 4, 5, or 6). E-cadherin expression was considered to be positive if $>90 \%$ of cancer cells exhibited a staining pattern similar to that in normal epithelial cells. Vimentin expression was classified as positive when $>10 \%$ cells were stained. $\beta$-Catenin nuclear staining was considered positive if $>10 \%$ of cells showed brown granules in nuclei.

\section{Plasmid transfection}

Transfection with plasmid carrying Wnt3a and controlled scrambled plasmid (Genechem, Shanghai, China) was performed with Lipofectamine 2000 (Invitrogen, Carlsbad, CA, USA) according to the manufacturer's instructions. To establish stable HCT116 cells that overexpressed Wnt3a, G418-resistant cells were screened.

\section{Western blot analysis}

Protein $(30-50 \mu \mathrm{g} /$ lane) was separated by $10 \%$ SDS-PAGE and transferred to polyvinylidene difluoride membranes. Blots were blocked and incubated with primary antibodies overnight at $4^{\circ} \mathrm{C}$, incubated with secondary antibody, and detected with ECL Western blot substrate (Millipore) according to the manufacturer's instructions.

\section{Soft agar colony formation assay}

To form bottom agar, $1.5 \mathrm{~mL}$ of culture medium containing $0.6 \%$ agarose was added to each $35 \mathrm{~mm}$ dish. Then, $1 \mathrm{~mL}$ of culture medium containing $0.6 \%$ agarose and $1 \times 10^{4}$ cells were mixed gently at $37^{\circ} \mathrm{C}$ and plated onto the bottom agar. Dishes were incubated at $37^{\circ} \mathrm{C}$ and $5 \% \mathrm{CO}_{2}$. Six days later, colonies $(>50 \mu \mathrm{m})$ were counted from 10 random fields per dish.

\section{Matrigel invasion assay}

Matrigel (BD Biosciences) with a final concentration of $1.5 \mathrm{mg} / \mathrm{mL}$ was added to the upper surface of the chamber filter ( $8 \mu \mathrm{m}$ pore). Then, $200 \mu \mathrm{L}$ of cell suspension $\left(5 \times 10^{5}\right.$ cells $\left./ \mathrm{mL}\right)$ contained in serum-free medium was added to the upper chamber, and $300 \mu \mathrm{L}$ of culture medium supplemented with $20 \%$ FBS was added to the lower chamber. After incubation for $20 \mathrm{~h}$, the passed cells were fixed and stained.

\section{Immunofluorescence confocal microscopy}

Cells were cultured on sterile glass cover slips on the day before staining. Cells were fixed with $4 \%$ paraformaldehyde, quenched with $50 \mathrm{mmol} / \mathrm{L} \mathrm{NH}_{4} \mathrm{Cl}$, permeabilized in $0.2 \%$ Triton X-100, and blocked in 3\% BSA. The slips were incubated with the primary antibodies overnight at $4^{\circ} \mathrm{C}$, labeled with the specific secondary antibodies for $1 \mathrm{~h}$ in the dark, mounted, and visualized with a confocal laser scanning microscopy (Leica TCS SP5, Leica Microsystems).

\section{In vivo assay}

Twenty mice were randomly and evenly divided into two groups and given either $3 \times 10^{6}$ control or HCT116 cells overexpressing Wnt3a (clone7) by subcutaneous injection in right groin. Tumor size was measured every 3 days for 21 days. Tumor volumes were calculated using the following formula: volume $=[$ length $($ in millimeters) $\times$ width $^{2}$ [in square millimeters])/2. Tumor samples were formalin fixed and paraffin embedded.

\section{Statistical analysis}

SPSS v.16.0 software (SPSS Inc., Chicago, IL, USA) was used for data analysis. The associations between Wnt3a and clinicopathologic parameters and the differential expression of E-cadherin, vimentin and $\beta$-catenin between different Wnt3a expression level groups were assessed with Fisher's exact test and chi-square test. Differences or correlations between groups were assessed by the Mann-Whitney U-test, Student's t-test and Pearson's correlation test. Survival analysis was carried out according to Kaplan-Meier. Differences in survival curves were assessed using the log rank test. Significance was set at $P<0.05$.

\section{Results}

Wnt3a expression is increased in colon carcinomas and correlates with the clinical outcome of patients

Among 203 samples, 179 (88.2\%) showed positive Wnt3a expression, whereas the remaining $24(11.8 \%)$ were negative. Tumors were categorized as strong expression, weak expression, or negative for Wnt3a (Figure 1A). Relationships between Wnt3a expression levels in colon cancer and each clinicopathological parameter were analyzed Table 1). Wnt3a expression level in colon cancer was found to increase with decreased differentiation grade. Wnt3a was strongly expressed in samples with higher clinical stages and metastasis/recurrence. Wnt3a expression was not significantly correlated with gender, age, and tumor size. Differences in Wnt3a expression level within tumors were found, with strong Wnt3a expression observed in tumor cells located close to stroma, implicating that Wnt3a may be involved in tumor progression in colon cancer (Figure 1B). 


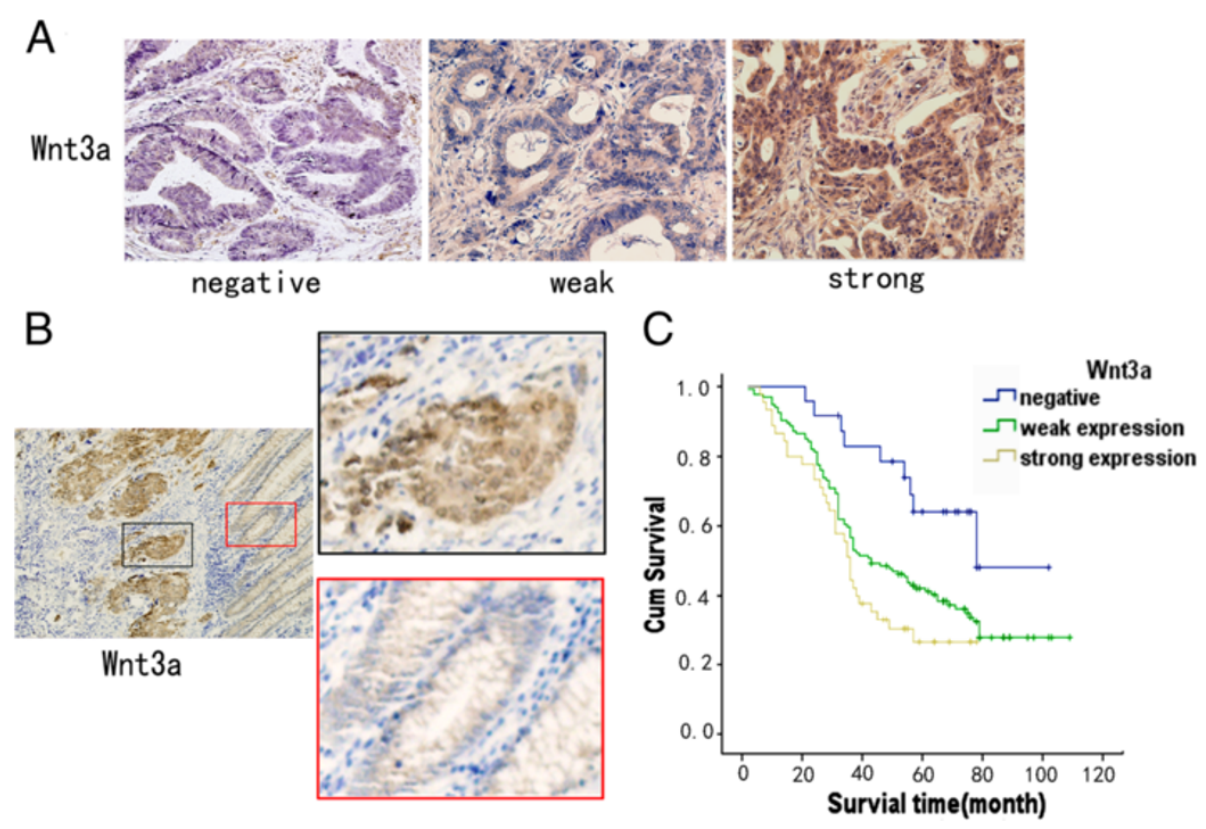

Figure 1 Expression of Wnt3a by immunohistochemical staining in human colon cancer tissue samples. (A) Representative colon cancer samples with Wnt3a negative (left), weak (middle), and strong (right) expression, 400x. (B) Strong expression of Wnt3a was observed in invasive front, 200x. (C) Kaplan-Meier survival analysis showing that Wnt3a-negative patients had longer survival time than Wnt3a-weak expression or Wnt3a-strong expression patients.

Table 1 Correlation between Wnt3a and clinicopathologic characteristics of patients with colon cancer

\begin{tabular}{|c|c|c|c|c|c|c|}
\hline \multirow[t]{2}{*}{ Viariant } & \multirow[t]{2}{*}{ Total } & \multicolumn{3}{|c|}{ Wnt3a expression } & \multirow[t]{2}{*}{$x^{2}$} & \multirow[t]{2}{*}{$P$ Value } \\
\hline & & Negative (\%) & Weak expression (\%) & Strong expression (\%) & & \\
\hline \multicolumn{7}{|l|}{$\overline{\text { Age }}$} \\
\hline$<45$ & 27 & $2(7.4)$ & $17(63)$ & $8(29.6)$ & \multirow[t]{2}{*}{1.340} & \multirow[t]{2}{*}{0.512} \\
\hline$\geq 45$ & 176 & $22(12.5)$ & $117(66.5)$ & $37(21.0)$ & & \\
\hline \multicolumn{7}{|l|}{ Sex } \\
\hline Male & 95 & $10(10.5)$ & $68(71.6)$ & $17(17.9)$ & \multirow[t]{2}{*}{2.563} & \multirow[t]{2}{*}{0.278} \\
\hline Female & 108 & $14(13)$ & $66(61.1)$ & $28(25.9)$ & & \\
\hline \multicolumn{7}{|l|}{ Tumor size } \\
\hline$\geq 5 \mathrm{~cm}$ & 166 & $6(9.1)$ & $41(62.1)$ & $19(28.8)$ & \multirow[t]{2}{*}{2.775} & \multirow[t]{2}{*}{0.250} \\
\hline$<5 \mathrm{~cm}$ & 137 & $18(13.1)$ & $93(67.9)$ & $26(19.0)$ & & \\
\hline \multicolumn{7}{|l|}{ Histological differentiation } \\
\hline Well differentiated & 16 & $5(31.2)$ & $10(62.5)$ & $1(6.2)$ & \multirow[t]{3}{*}{15.127} & \multirow[t]{3}{*}{$0.004^{*}$} \\
\hline Moderately differentiated & 101 & $11(10.9)$ & $74(73.3)$ & $16(15.8)$ & & \\
\hline Poorly differantiated & 86 & $8(9.3)$ & $50(58.1)$ & $28(32.6)$ & & \\
\hline \multicolumn{7}{|l|}{ Clinical stage } \\
\hline TNMI & 10 & $5(50.0)$ & $4(40.0)$ & $1(10.0)$ & \multirow[t]{4}{*}{17.456} & \multirow[t]{4}{*}{$0.008^{*}$} \\
\hline TNMII & 128 & $15(11.7)$ & $86(67.2)$ & $27(21.1)$ & & \\
\hline TNMIII & 54 & $4(7.4)$ & $37(68.5)$ & $13(24.1)$ & & \\
\hline TNMIV & 11 & $0(0.0)$ & 7 (63.6) & $4(36.4)$ & & \\
\hline \multicolumn{7}{|l|}{ Metastasis/recurrence } \\
\hline Absent & 135 & $20(14.8)$ & $91(67.4)$ & $24(17.8)$ & \multirow[t]{2}{*}{6.674} & \multirow[t]{2}{*}{$0.036^{*}$} \\
\hline Present & 68 & $4(5.9)$ & $43(63.2)$ & $21(30.9)$ & & \\
\hline
\end{tabular}

*Significantly different. 
Furthermore, Kaplan-Meier survival analysis showed that the total survival time for patients in the Wnt3anegative group was significantly longer than for those in the Wnt3a-weak expression or Wnt3a-strong expression group $(P=0.007)$. The average survival time for Wnt3anegative patients was 76.4 months, whereas the average survival time for Wnt3a-weak expression and Wnt3astrong expression group patients were 57.6 and 41.7 months respectively (Figure $1 \mathrm{C}$ ).

\section{Wnt3a expression was concomitant with EMT immunohistochemical features}

To assess the relationship between Wnt3a and EMT in colon cancer, we investigated the expression of the EMTassociated markers E-cadherin, vimentin, and $\beta$-catenin (also a marker of Wnt/ $\beta$-catenin pathway activation). As shown in Table 2 and Figure 2, the Wnt3a-negative group showed higher E-cadherin expression and lower vimentin and nuclear $\beta$-catenin expression than the positive group. $\beta$-Catenin was mainly expressed in cytoplasm in the Wnt3a-negative group and in the nucleus in the positive group. The expression of Wnt3a correlated with the expression of E-cadherin $(r=-0.208, P<0.05)$, vimentin ( $r=0.247, P<0.001)$, and $\beta$-catenin (nuclear) $(r=0.194$, $P<0.05)$. These data provided proof about the role of Wnt3a as a potent activator of Wnt/ $\beta$-catenin signaling and as a regulator involved in tumor progression in colon cancer.

Wnt3a overexpression induced mesenchymal phenotype and increased expression of Snail in HCT116 cells

We established stable Wnt3a-overexpressed colon cancer cells to study the EMT-promoting effect of Wnt3a on colorectal cancer cells. To rule out clone-to-clone variations, we selected two clones (clone7 and clone15). HCT116 cells with Wnt3a overexpression had increased expression of c-myc and cyclin D1 (Figure 3A), which are the best-known target proteins of canonical Wnt signaling $[19,20]$, thereby confirming activation of the signaling pathway.

EMT is a multistep process in which cells undergo molecular alterations that facilitate dysfunctional cell-cell adhesive interactions and reorganization of cytoskeleton, resulting in loss of apical polarity and acquisition of a more spindle-shaped morphology. Thus, we used phalloidin to dye fibrous actin (F-actin), a representative of cytoskeleton, and observed that Wnt3a overexpression caused HCT116 cells to form structures with irregular shape and non-uniform composition or density (Figure 3B). Western blot and immunofluorescence assays demonstrated that cells overexpressing Wnt3a had lower expression of E-cadherin and higher expression of vimentin than control cells (Figure 3C and 3D). In addition to classical EMT markers, we examined the expression of the EMT transcription factors Snail, Slug, and Twist. These markers could repress E-cadherin expression by direct binding to the E-boxes of the E-cadherin promoter. Among them, Snail was upregulated in cells overexpressing Wnt3a compared with control cells, whereas the expression of Slug and Twist did not significantly change (Figure 3C). Moreover, although total $\beta$-catenin expression did not markedly change in Western blot detection, immunofluorescence showed that more $\beta$-catenin accumulated in the nucleus of cells overexpressing Wnt3a than in that of control cells (Figure 3D). All these findings suggested that cells overexpressing Wnt3a were more predisposed to mesenchymal differentiation.

Wnt3a promotes in vitro clone-initiating and invasion abilities, in vivo tumor growth and metastasis of HCT116 cells

Anchorage-independent growth, one of the most important malignant features of cancer cell stemness, was found to be significantly increased in cells overexpressing Wnt3a (Figure 4A).

Compared with epithelial cells, mesenchymal cells generally defined cell polarity, cytoskeletal structures

Table 2 Correlation between expression of Wnt3a and EMT-associated proteins

\begin{tabular}{|c|c|c|c|c|c|c|}
\hline \multirow[t]{2}{*}{ Variant } & \multirow[t]{2}{*}{ Total } & \multicolumn{3}{|c|}{ Wnt3a expression } & \multirow[t]{2}{*}{$x^{2}$} & \multirow[t]{2}{*}{$P$ Value } \\
\hline & & Negative (\%) & Weak expression (\%) & Strong expression (\%) & & \\
\hline \multicolumn{7}{|c|}{ E-cadherin expression } \\
\hline Negative & 16 & $0(0.0)$ & $8(50.0)$ & $8(50.0)$ & 8.798 & $0.012^{*}$ \\
\hline Positive & 187 & $24(12.8)$ & $126(67.4)$ & $37(19.8)$ & & \\
\hline \multicolumn{7}{|c|}{ Vimentin expression } \\
\hline Negative & 187 & $24(12.8)$ & $127(67.9)$ & $36(19.3)$ & 12.459 & $0.002^{*}$ \\
\hline Positive & 16 & $0(0.0)$ & $7(43.8)$ & $9(56.2)$ & & \\
\hline \multicolumn{7}{|c|}{$\beta$-catenin nuclear expression } \\
\hline Negative & 167 & $22(13.2)$ & $114(68.3)$ & $31(18.6)$ & 7.698 & $0.021^{*}$ \\
\hline Positive & 36 & $2(5.6)$ & $20(55.6)$ & $14(38.9)$ & & \\
\hline
\end{tabular}

*Significantly different. 


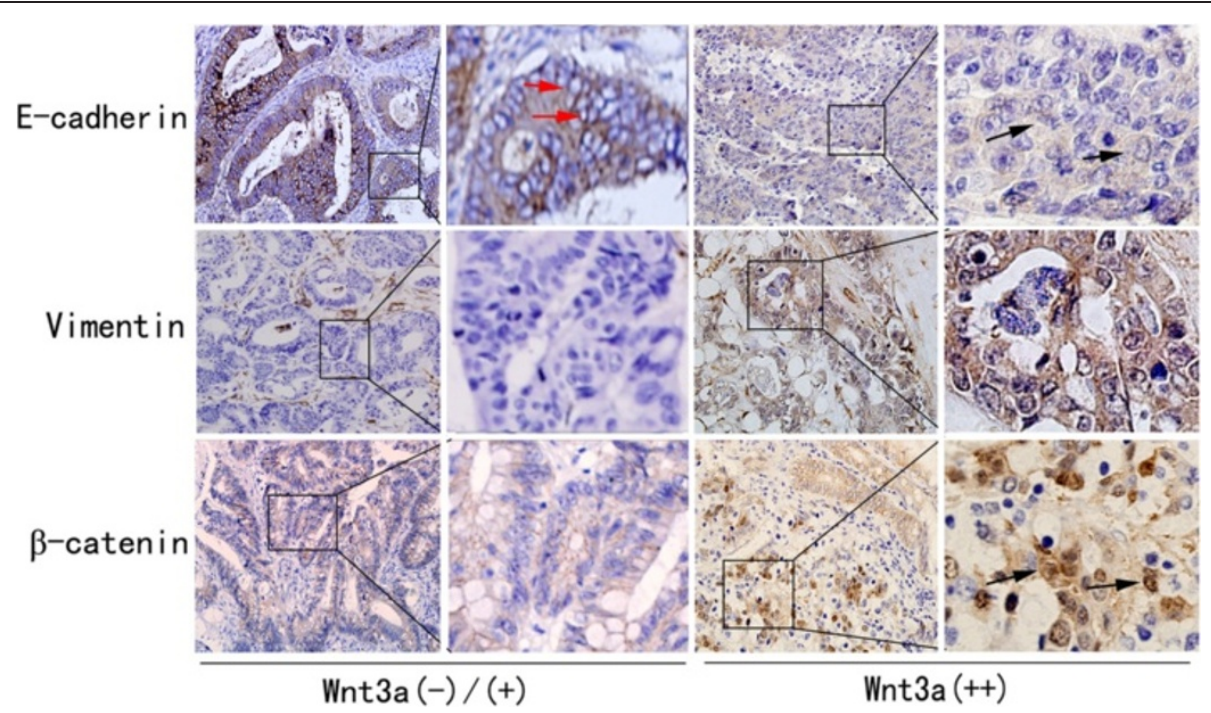

Figure 2 Wnt3a expression was concomitant with EMT immunohistochemical features in human colon cancer tissue samples. E-cadherin expression was higher in Wnt3a negative (-) or weak expression (+) colon cancer tissue sections than in strong-expression (++) samples. E-cadherin was mainly localized in membrane of Wnt3a $(-) /(+)$ samples (red arrows) and in cytoplasm of Wnt3a (++) samples (black arrows). Tumor cells in Wnt3a $(-) /(+)$ section did not express vimentin, whereas several tumor cells in Wnt3a $(++)$ section showed expression of vimentin. In Wnt3a $(-) /(+)$ sections, tumor cells displayed weak and only membrane-localized $\beta$-catenin expression, whereas tumor cells in Wnt3a (++) section showed nuclear $\beta$-catenin accumulation (black arrows), 400x.

and cell-ECM interactions. Thus, the process of EMT can directly lead to increased invasive potential of tumor cells. As expected, more cells overexpressing Wnt3a invaded through the Matrigel than control cells (Figure 4B).

In agreement with in vitro findings, clone7 cells overexpressing Wnt3a grew into larger tumor masses than control cells (Figure 4C). To assess canonical Wnt signal activity in xenografts, we then performed $\beta$-catenin immunohistochemical staining on the sections of xenograft tissues. The nuclear expression of $\beta$-catenin significantly increased in Wnt3a tumors compared with control tumors (Figure 4D). Among the 10 mice injected with clone7 cells, one showed lung metastasis and one showed lymph node methastasis (Figure 4E). Meanwhile, among the 10 mice injected with control cells, no mouse showed lymph node or lung metastasis and only two showed tumor invasion into the surrounding fatty tissue.

Dkk1 abolishes the expression of EMT-associated proteins in Wnt3a-overexpressing HCT116 cells

To verify whether the EMT promotion effect of Wnt3a was due to $\mathrm{Wnt} / \beta$-catenin pathway activation, we utilized the $\mathrm{Wnt} / \beta$-catenin pathway inhibitor Dkk1. Dkk1 functions as an antagonist of the Wnt/ $\beta$-catenin pathway by binding to lipoprotein receptor-related protein 5 or 6 (LRP5/6) and preventing the formation of Wnt-Fz-LRP ternary complexes and the downstream signaling transduction. After Dkk1 treatment, Wnt3a-overexpressing cells showed decreased $\beta$-catenin expression, indicating the effectiveness of Dkk1 as an inhibitor of Wnt/ $\beta$-catenin pathway. Western blot assays also demonstrated that Wnt3a-overexpressing cells treated with Dkk1 had higher expression of E-cadherin and lower expression of vimentin, Snail, and Twist compared with untreated cells (Figure 5). This finding indicated that $\mathrm{Wnt} / \beta$ catenin pathway activation played an important role in the EMT-inducing effect of Wnt3a. Meanwhile, Dkk1 did not restore the expression of EMT-associated proteins in Wnt3a-overexpressing cells to the same level as the control cells, suggesting that Wnt3a may promote EMT through distinct mechanisms other than activating the $\mathrm{Wnt} / \beta$-catenin pathway.

\section{Discussion}

Wnt3a is a Wnt protein that activates the canonical Wnt pathway. Wnt3a stimulates tumor progression in glioblastoma [22], breast and prostate cancers [23,24], and malignant mesothelioma [25]. Other studies have shown that Wnt3a serves as a tumor suppressor based on two main findings. One is that bones engrafted with Wnt3a-expressing multiple myeloma H929 cells are preserved; the other is that treatment of myelomatous SCID mice carrying the primary disease with recombinant Wnt3a stimulates bone formation and attenuates multiple myeloma growth [26]. Marit et al. reported that Wnt3a inhibits the proliferation of several B-acute lymphoblastic leukemia cell lines [27]. In the present study, we initially analyzed Wnt3a expression in a large array of colon cancer tissue samples to determine its role 


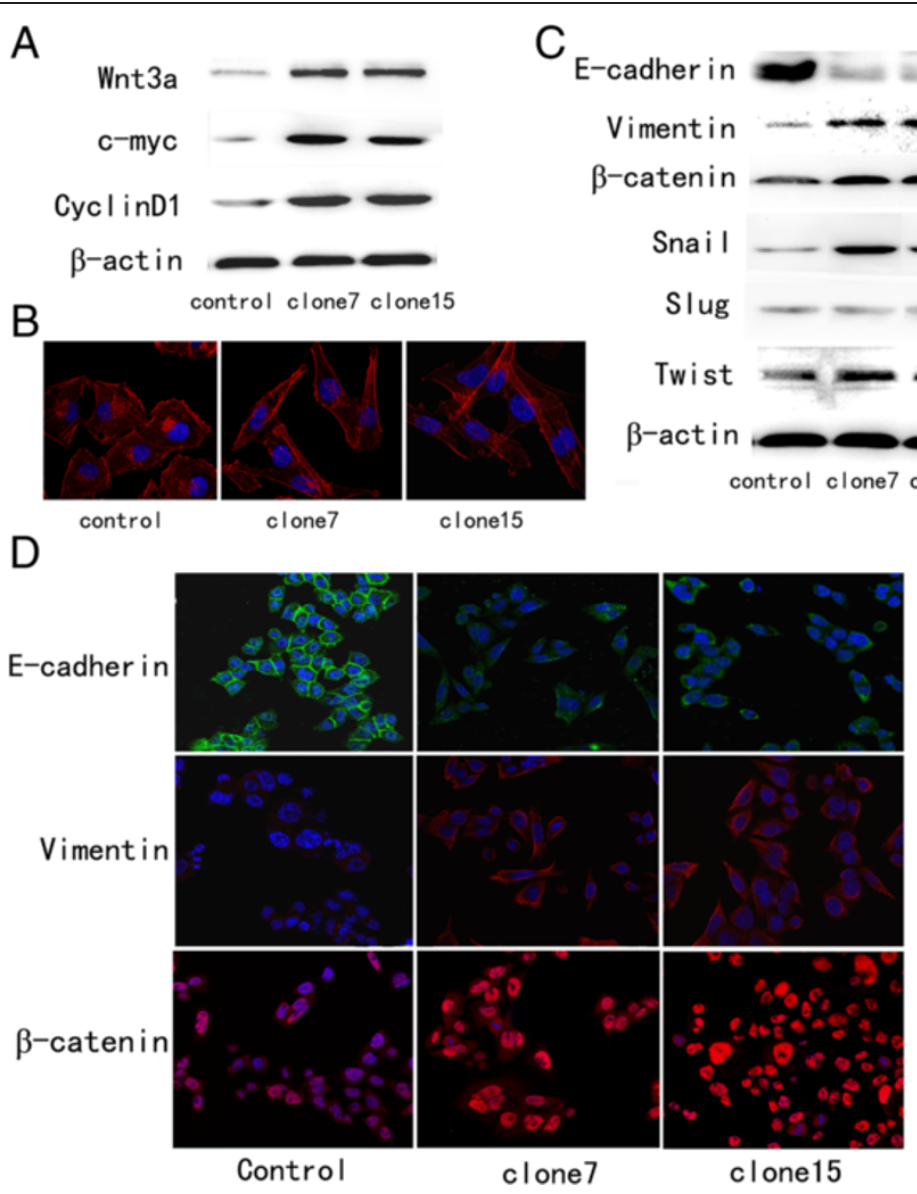

Figure 3 Wnt3a overexpression induced mesenchymal phenotype and increased expression of mesenchymal markers. (A) Wnt3a protein levels were significantly increased in clone7 and clone15 HCT116 cell pools transfected with Wnt3a plasmid. Then, c-myc and CyclinD1 protein expression increased in clone7 and clone15 HCT116 cell. (B) Immunofluorescent staining of F-actin. Wnt3a-overexpressing cells exhibited dramatic changes in cell morphology from a tight packed, polarized, and epithelial-like appearance to a scattered, irregular, and fibroblastic-like shape. (C) Wnt3a-overexpressing cells showed lower E-cadherin expression but higher vimentin expression. $\beta$-Catenin expression did not markedly change in three groups of cells. EMT regulatory proteins including Snail, Slug, and Twist were detected. Snail was upregulated in Wnt3a-overexpressing cells compared with control cells, whereas Slug and Twist expression did not significantly change. (D) Immunofluorescent staining of E-cadherin, vimentin, and $\beta$-catenin. Wnt3a-overexpressing cells showed lower E-cadherin expression and higher vimentin expression. More $\beta$-catenin accumulation in nucleus was observed in Wnt3a-overexpressing cells than in control cells. A green or red signal represents staining for corresponding protein, whereas a blue signal represents nuclear DNA staining by 4',6-diamidino-2-phenylindole.

in colon-cancer progression. We observed a significant correlation between Wnt3a expression and histological differentiation, clinical stages, metastasis, and recurrence, indicating that the upper stream factor of the Wnt signaling pathway may play an important role in colon-cancer progression. This result was consistent with a recent study on colorectal cancer, in which results reveal that Wnt3a is highly expressed in the primary and metastatic sites and is significantly associated with expression of the metastasis-related protein matrix metalloproteinase (MMP)-9 [28].

EMT is involved in numerous normal developmental processes and in cancer progression. EMT involves biochemical changes that result in decreased expression of the epithelial marker E-cadherin but increased expression of mesenchymal markers, such as vimentin. Cancer cells undergoing EMT are suitable for migration, invasion, and proliferation, thereby facilitating tumor progression. EMT involves different regulatory signaling pathways. Although the effects of Wnt/ $\beta$-catenin signaling in promoting EMT during physiological or pathological processes have been extensively studied, the present study was the first to demonstrate the EMT-inducing ability of Wnt3a in colon cancer. In human colon cancer tissue samples, lower levels of E-cadherin expression, as well as higher levels of vimentin expression and $\beta$-catenin nuclear distribution, were observed in the Wnt3a strong group than in the weak and negative expression groups. This finding suggested that Wnt3a may contribute to EMT in colon cancer. EMT induction in colon cancer cells by Wnt3a was confirmed 
A

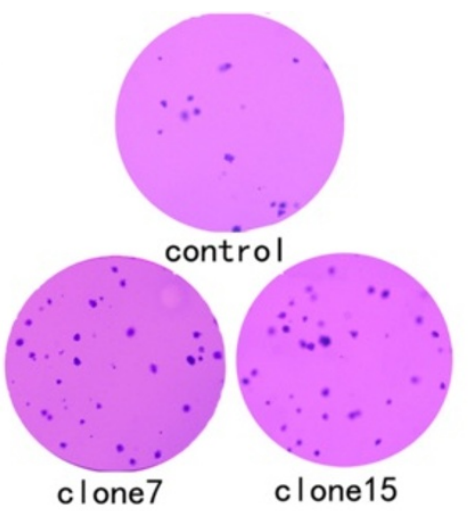

B
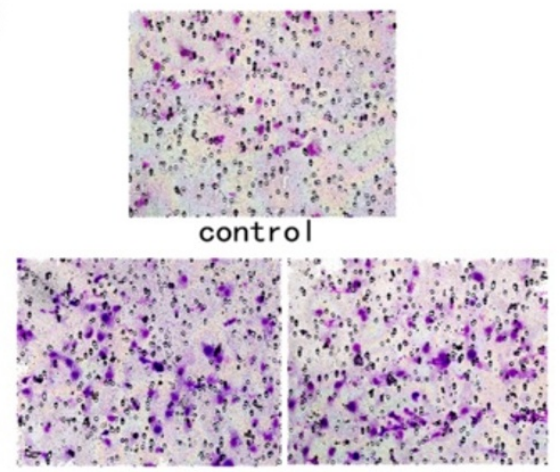

clone7

C
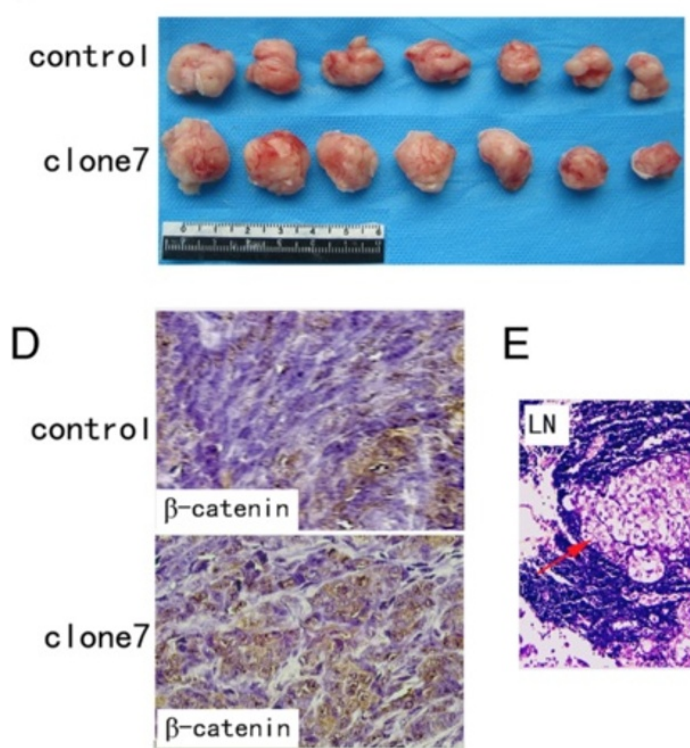
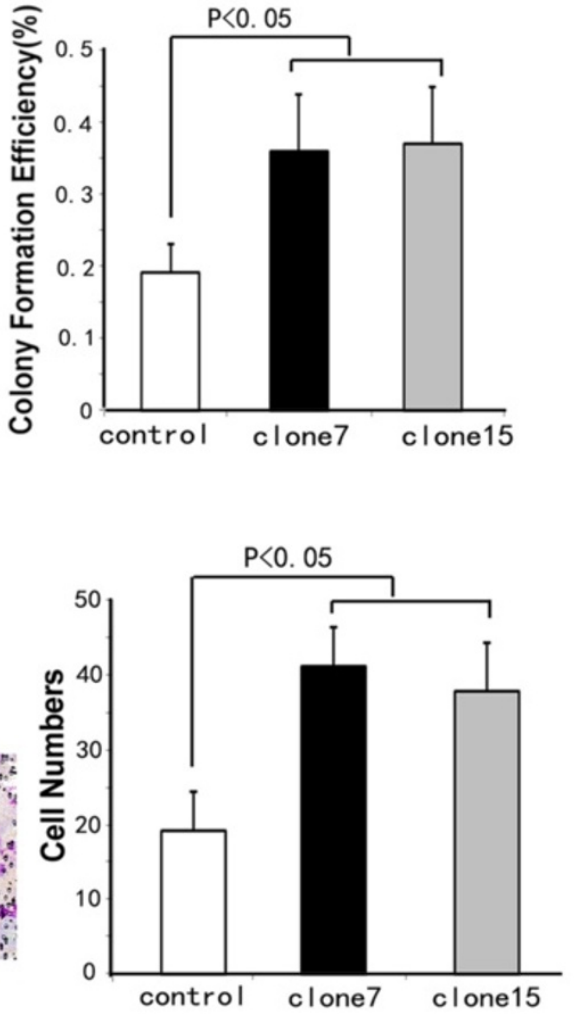

$E$

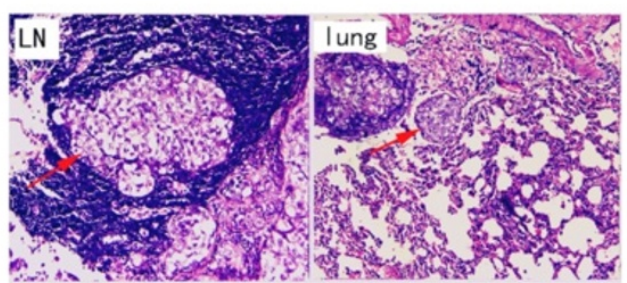

Figure 4 Effect of Wnt3a overexpression on in vitro clone-initiation and invasion abilities and in vivo tumor growth and metastasis. (A) Wnt3a overexpression promoted HCT116 anchorage-independent growth in soft agar. Colonies in soft agar culture were stained (left), 200X. Histogram showing colony formation efficiency (right). (B) Cells invading through matrigel-coated transwell inserts were stained (left), 200x. Invading cells were counted in five pre-determined fields (right), 400x. (C) Photograph of representative tumors from mice injected with control or Wnt3a transfected HCT116 cells (clone7) (left). Wnt3a-overexpressing cells produced larger tumor masses than control cells (right). (D) Immunohistochemical staining of $\beta$-catenin expression in harvested mouse tumor samples. Tumors overexpressing Wnt3a (clone7) exhibited increased nuclear $\beta$-catenin expression compared with control tumors, 400x. (E) Mice injected with Wnt3a-overexpressing cells (clone7) showed lymph node metastasis and lung metastasis (red arrows); hematoxylin and eosin staining, $200 \times$. 


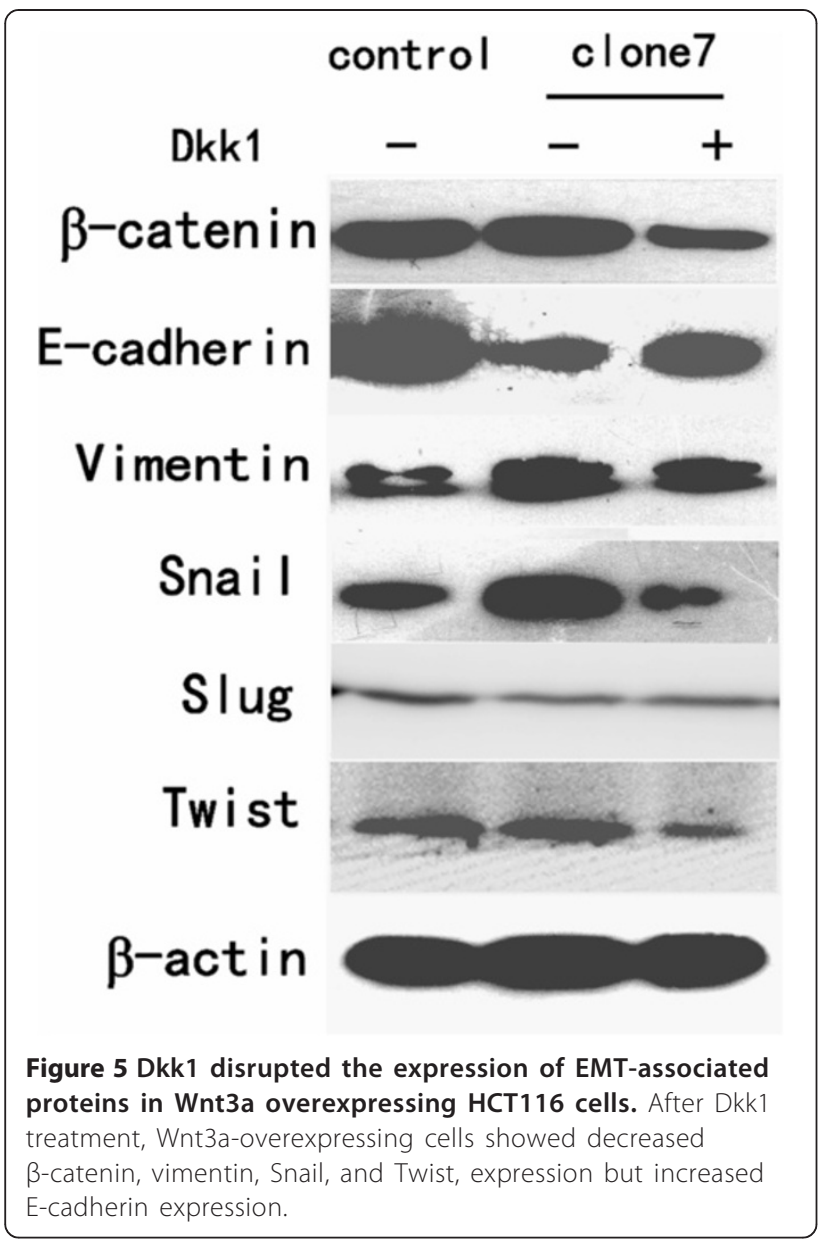

through the altered morphology and expression of the EMT-associated markers, as well as enhanced invasion capacities. Moreover, previous reports have indicated that cancer cells undergoing EMT share the properties of stem cell-like cells [29-31].

In the present study, we found that Wnt3a overexpression could promote colon-cancer cell growth in anchorage-independent growth in soft agar and increased the expression of c-myc, which is a major target molecule of transcription T-cell factor/lymphoid enhancer factor (TCF/LEF) promoter and also a cancer stem cell marker. We further demonstrated that Wnt3a could promote the expression of Snail, which is a key transcription EMT regulator. We also found that Wnt3a has significant stimulative effects on tumor growth and metastasis in nude mice. These findings demonstrated that ectopic Wnt3a expression exerted EMT-inducing effects that promote the progression of colon cancer. Meanwhile, another study on hepatocellular carcinoma showed that recombinant Wnt3a could not induce Huh-7 or HepG2 cells to undergo EMT in normoxia. Yoshida also indicated that oxidative stress could induce canonical Wnt activation.
All these observations emphasize the importance of the microenvironment for Wnt signaling and EMT [32,33]. We suggested that the inconsistencies may be attributed to the different cell types and tissues.

$\beta$-Catenin has a dual cellular function and is involved in both transcription regulation and cell adhesion. When Wnt ligands such as Wnt1, Wnt3a, and Wnt7a act on their cell-surface receptors, cytoplasmic $\beta$-catenin is stabilized by its release from the axin complex and accumulation in the nucleus, where it binds to TCF/LEF and stimulates the expression of various genes involved in EMT [34]. $\beta$-Catenin has also been identified as a cadherin-binding protein. The nuclear translocation of $\beta$-catenin leads to the breakdown of cell-to-cell adhesion formed by $\beta$-catenin and E-cadherin. This phenomenon has been extensively studied in both morphological and biochemical EMT processes regardless of inducers and origins [35]. Our results showed that ectopic Wnt3a expression in HCT116 increased the expression and intracellular distribution of $\beta$-catenin and of the wellestablished target proteins of $\mathrm{Wnt} / \beta$-catenin signaling, namely, c-myc, and cyclin D1. However, the inhibition of Wnt/ $\beta$-catenin signaling by Dkk1 disrupted Wnt3ainduced EMT. All results indicated that the EMTinducing effect of Wnt3a in colon cancer may be at least partially due to the stimulative effect of Wnt3a on the $\mathrm{Wnt} / \beta$-catenin pathway.

After treating with Dkk1, the expression of EMTassociated proteins in Wnt3a-overexpressing cells did not recover to the same level as that of control cells. Thus, a Wnt3a-induced EMT mechanism that is independent of the Wnt/ $\beta$-catenin pathway may exist. Another possibility was that the cancer cells may be responsive to Dkk1 differently in 2-D versus 3-D cultures, which more closely mimic the in vivo environment [36,37].

Multiple interactions were observed between Wnt3a and other families of signaling molecules, such as FAK, TGF- $\beta$, and EGF [38-41]. Nalesso reported that Wnt3a could activate both canonical and non-canonical Wnt pathways in the articular chondrocyte [42]. Sonderegger reported that Wnt3a could activate phosphatidylinositide3kinase (PI3K)/AKT signaling, which could potentially cross-talk to canonical Wnt signaling and affect MMP-2 secretions to promote the invasion of human trophoblasts [43]. Studies designed to elucidate the interactions of Wnt3a with other EMT-associated signaling pathways in colon cancer are currently under way.

In conclusion, we showed that Wnt3a expression activated the $\mathrm{Wnt} / \mathrm{\beta}$-catenin signaling pathway, and this activation was a mechanism underlying EMT in colon cancer. The results provide better understanding of the importance of EMT in tumor development and may enable the establishment of clinically useful therapy targets. 


\section{Competing interests}

The authors declare that they have no competing interest.

\section{Authors' contributions}

Conceived and designed the experiments: SBC QLS. Performed the experiments: QLS LZY CRF LYX. Analyzed the data: LZY. Contributed reagents/materials/analysis tools: SBC ZXL. Wrote the paper: QLS. All authors read and approved the final manuscript.

\section{Acknowledgments}

This study was supported by the Key Project of the National Natural Science Foundation of China (No. 81230050), the National Natural Science Foundation of China (No. 81402420, No. 81173091 and No. 81172046), the Key Project of Tianjin Natural Science Foundation (No. 12JCZDJC23600) and the Science Foundation of Tianjin Medical University (NO. 2013KYQ08).

\section{Author details}

${ }^{1}$ Department of Pathology, Tianjin Medical University Cancer Institute and Hospital, Tianjin 300060, China. ${ }^{2}$ Department of Pathology, Tianjin Medical University, Tianjin 300070, China. ${ }^{3}$ The Key Laboratory of Tianjin Cancer Prevention and Treatment, Tianjin 300060, China. ${ }^{4}$ National Clinical Research Center for Cancer, Tianjin 300060, China.

Received: 12 July 2014 Accepted: 1 December 2014

Published online: 11 December 2014

\section{References}

1. Ferlay J, Shin HR, Bray F, Forman D, Mathers C, Parkin DM: Estimates of worldwide burden of cancer in 2008: GLOBOCAN 2008. Int J Cancer 2010, 127:2893-2917.

2. Sanjoaquin MA, Choodari-Oskooei B, Dolbear C, Putcha V, Sehgal A, Key TJ, Moller H: Colorectal cancer incidence, mortality and survival in South-east England between 1972 and 2001. Eur J Cancer Prev 2007, 16:10-16.

3. Ding S, Zhang W, Xu Z, Xing C, Xie H, Guo H, Chen K, Song P, Gu Y, Xiao F, Zhou L, Zheng S: Induction of an EMT-like transformation and MET in vitro. J Transl Med 2013, 11:164.

4. Miao CG, Yang YY, He X, Li XF, Huang C, Huang Y, Zhang L, LV XW, Jin Y, Li $\mathrm{J}$ : Wnt signaling pathway in rheumatoid arthritis, with special emphasis on the different roles in synovial inflammation and bone remodeling. Cell Signal 2013, 25:2069-2078.

5. Miki T, Yasuda SY, Kahn M: Wnt/beta-catenin signaling in embryonic stem cell self-renewal and somatic cell reprogramming. Stem Cell Rev 2011, 7:836-846.

6. de Sousa EM, Vermeulen L, Richel D, Medema JP: Targeting Wnt signaling in colon cancer stem cells. Clin Cancer Res 2011, 17:647-653.

7. Pawlikowski JS, McBryan T, van Tuyn J, Drotar ME, Hewitt RN, Maier AB, King A, Blyth K, Wu H, Adams PD: Wnt signaling potentiates nevogenesis. Proc Natl Acad Sci U S A 2013, 110:16009-16014.

8. Yang L, Perez AA, Fujie S, Warden C, Li J, Wang Y, Yung B, Chen YR, Liu X, Zhang H, Zheng S, Liu Z, Ann D, Yen Y: Wnt modulates MCL1 to control cell survival in triple negative breast cancer. BMC Cancer 2014, 14:124.

9. Ramachandran I, Thavathiru E, Ramalingam S, Natarajan G, Mills WK, Benbrook DM, Zuna R, Lightfoot S, Reis A, Anant S, Queimado L: Wnt inhibitory factor 1 induces apoptosis and inhibits cervical cancer growth, invasion and angiogenesis in vivo. Oncogene 2012, 31:2725-2737.

10. Mikels AJ, Nusse R: Wnts as ligands: processing, secretion and reception. Oncogene 2006, 25:7461-7468.

11. Voloshanenko O, Erdmann G, Dubash TD, Augustin I, Metzig M, Moffa G, Hundsrucker C, Kerr G, Sandmann T, Anchang B, Demir K, Boehm C, Leible $S$, Ball CR, Glimm H, Spang R, Boutros M: Wnt secretion is required to maintain high levels of Wnt activity in colon cancer cells. Nat Commun 2013, 4:2610.

12. Clevers $\mathrm{H}$ : Wnt/beta-catenin signaling in development and disease. Cell 2006, 127:469-480.

13. Widelitz R: Wnt signaling through canonical and non-canonical pathways: recent progress. Growth Factors 2005, 23:111-116.

14. Li X, Xu Y, Chen Y, Chen S, Jia X, Sun T, Liu Y, Xiang R, Li N: SOX2 promotes tumor metastasis by stimulating epithelial-to-mesenchymal transition via regulation of WNT/beta-catenin signal network. Cancer Lett 2013, 336:379-389.
15. Huang J, Xiao D, Li G, Ma J, Chen P, Yuan W, Hou F, Ge J, Zhong M, Tang Y, Xia X, Chen Z: EphA2 promotes epithelial-mesenchymal transition through the Wnt/beta-catenin pathway in gastric cancer cells. Oncogene 2014, 33:2737-2747.

16. Blavier L, Lazaryev A, Shi XH, Dorey FJ, Shackleford GM, DeClerck YA: Stromelysin-1 (MMP-3) is a target and a regulator of Wnt1-induced epithelial-mesenchymal transition (EMT). Cancer Biol Ther 2010, 10:198-208.

17. Bo H, Zhang S, Gao L, Chen Y, Zhang J, Chang X, Zhu M: Upregulation of Wnt5a promotes epithelial-to-mesenchymal transition and metastasis of pancreatic cancer cells. BMC Cancer 2013, 13:496-506.

18. Kanzawa M, Semba S, Hara S, Itoh T, Yokozaki H: WNT5A is a key regulator of the epithelial-mesenchymal transition and cancer stem cell properties in human gastric carcinoma cells. Pathobiology 2013, 80:235-244.

19. Wu Y, Ginther C, Kim J, Mosher N, Chung S, Slamon D, Vadgama JV: Expression of Wnt3 activates Wnt/beta-catenin pathway and promotes EMT-like phenotype in trastuzumab-resistant HER2-overexpressing breast cancer cells. Mol Cancer Res 2012, 10:1597-1606.

20. Bao XL, Song H, Chen Z, Tang X: Wnt3a promotes epithelial-mesenchymal transition, migration, and proliferation of lens epithelial cells. Mol Vis 2012, 18:1983-1990.

21. Zhang S, Qi L, Li M, Zhang D, Xu S, Wang N, Sun B: Chemokine CXCL12 and its receptor CXCR4 expression are associated with perineural invasion of prostate cancer. J Exp Clin Cancer Res 2008, 27:62.

22. Kaur N, Chettiar S, Rathod S, Rath P, Muzumdar D, Shaikh ML, Shiras A: Wnt3a mediated activation of Wnt/beta-catenin signaling promotes tumor progression in glioblastoma. Mol Cell Neurosci 2013, 54:44-57.

23. Lamb R, Ablett MP, Spence K, Landberg G, Sims AH, Clarke RB: Wnt pathway activity in breast cancer sub-types and stem-like cells. PLOS ONE 2013, 8:e67811.

24. Verras M, Brown J, Li X, Nusse R, Sun Z: Wnt3a growth factor induces androgen receptor-mediated transcription and enhances cell growth in human prostate cancer cells. Cancer Res 2004, 64:8860-8866.

25. Fox SA, Richards AK, Kusumah I, Perumal V, Bolitho EM, Mutsaers SE, Dharmarajan AM: Expression profile and function of Wnt signaling mechanisms in malignant mesothelioma cells. Biochem Biophys Res Commun 2013, 440:82-87.

26. Qiang YW, Shaughnessy JD Jr, Yaccoby S: Wnt3a signaling within bone inhibits multiple myeloma bone disease and tumor growth. Blood 2008, 112:374-382.

27. Nygren MK, Dosen G, Hystad ME, Stubberud H, Funderud S, Rian E: Wnt3A activates canonical Wnt signalling in acute lymphoblastic leukaemia (ALL) cells and inhibits the proliferation of B-ALL cell lines. Br J Haematol 2007, 136:400-413.

28. Lee MA, Park JH, Rhyu SY, Oh ST, Kang WK, Kim HN: Wnt3a expression is associated with MMP-9 expression in primary tumor and metastatic site in recurrent or stage IV colorectal cancer. BMC Cancer 2014, 14:125-131.

29. Prasad CP, Rath G, Mathur S, Bhatnagar D, Parshad R, Ralhan R: Expression analysis of E-cadherin, Slug and GSK3beta in invasive ductal carcinoma of breast. BMC Cancer 2009, 9:325-334.

30. Li J, Zhou BP: Activation of beta-catenin and Akt pathways by Twist are critical for the maintenance of EMT associated cancer stem cell-like characters. BMC Cancer 2011, 11:49-59.

31. Scheel C, Weinberg RA: Cancer stem cells and epithelial-mesenchymal transition: concepts and molecular links. Semin Cancer Biol 2012, 22:396-403.

32. Zhang Q, Bai X, Chen W, Ma T, Hu Q, Liang C, Xie S, Chen C, Hu L, Xu S, Liang T: Wnt/beta-catenin signaling enhances hypoxia-induced epithelial-mesenchymal transition in hepatocellular carcinoma via crosstalk with hif-1alpha signaling. Carcinogenesis 2013, 34:962-973.

33. Yoshida GJ, Saya H: Inversed relationship between CD44 variant and c-Myc due to oxidative stress-induced canonical Wnt activation. Biochem Biophys Res Commun 2014, 443:622-627.

34. Clevers H, Nusse R: Wnt/beta-catenin signaling and disease. Cell 2012, 149:1192-1205.

35. Schafer G, Narasimha M, Vogelsang E, Leptin M: Cadherin switching during the formation and differentiation of the Drosophila mesoderm - implications for epithelial-to-mesenchymal transitions. J Cell Sci 2014, 127:1511-1522.

36. Ludwig. K, E. S. Tse, JY. Wang, Colon cancer cells adopt an invasive phenotype without mesenchymal transition in 3-D but not 2-D culture upon combined stimulation with EGF and crypt growth factors, BMC Cancer 13 (2013) 221-232. 
37. Yoshida GJ, Saya H, Zouboulis CC: Three-dimensional culture of sebaceous gland cells revealing the role of prostaglandin E2-induced activation of canonical Wnt signaling. Biochem Biophys Res Commun 2013, 438:640-646.

38. Ayyanan A, Civenni G, Ciarloni L, Morel C, Mueller N, Lefort K, Mandinova A, Raffoul W, Fiche M, Dotto GP, Brisken C: Increased Wnt signaling triggers oncogenic conversion of human breast epithelial cells by a Notchdependent mechanism. Proc Natl Acad Sci U S A 2006, 103:3799-3804.

39. van den Bosch $M H$, Blom $A B$, van Lent $P L$, van Beuningen $H M$, Blaney Davidson EN, van der Kraan PM, van den Berg WB: Canonical Wnt signaling skews TGF-beta signaling in chondrocytes towards signaling via ALK1 and Smad 1/5/8. Cell Signal 2014, 26:951-958.

40. Despeaux M, Chicanne G, Rouer E, De Toni-Costes F, Bertrand J, MansatDe Mas V, Vergnolle N, Eaves C, Payrastre B, Girault JA, Racaud-Sultan C: Focal adhesion kinase splice variants maintain primitive acute myeloid leukemia cells through altered Wnt signaling. Stem Cells 2012, 30:1597-1610.

41. Kim SE, Choi KY: EGF receptor is involved in WNT3a-mediated proliferation and motility of NIH3T3 cells via ERK pathway activation. Cell Signal 2007, 19:1554-1564.

42. Nalesso G, Sherwood J, Bertrand J, Pap T, Ramachandran M, De Bari C, Pitzalis C, Dell'accio F: WNT-3A modulates articular chondrocyte phenotype by activating both canonical and noncanonical pathways. J Cell Biol 2011, 193:551-564.

43. Sonderegger S, Haslinger P, Sabri A, Leisser C, Otten JV, Fiala C, Knofler M: Wingless (Wnt)-3A induces trophoblast migration and matrix metalloproteinase-2 secretion through canonical Wnt signaling and protein kinase B/AKT activation. Endocrinology 2010, 151:211-220.

doi:10.1186/s13046-014-0107-4

Cite this article as: Qi et al:: Wnt3a expression is associated with epithelial-mesenchymal transition and promotes colon cancer progression. Journal of Experimental \& Clinical Cancer Research 2014 33:107.

\section{Submit your next manuscript to BioMed Central and take full advantage of:}

- Convenient online submission

- Thorough peer review

- No space constraints or color figure charges

- Immediate publication on acceptance

- Inclusion in PubMed, CAS, Scopus and Google Scholar

- Research which is freely available for redistribution 